\title{
Prognostic factors for ARDS: clinical, physiological and atypical immunodeficiency
}

\author{
Min Song ${ }^{1,2}$, Yijie Liu', Zhiwen Lü ${ }^{3}$, Hong Luo ${ }^{1,2^{*}}$, Hong Peng ${ }^{1,2}$ and Ping Chen ${ }^{1,2}$
}

\begin{abstract}
Background: Risk factors affecting the prognosis of acute respiratory distress syndrome (ARDS) in adults were investigated. The aim was to identify new predictors for ARDS patient prognosis, including those with clinical, pathophysiological, and atypical immunodeficiency.

Methods: ARDS patients were retrospectively included. The patients were grouped and analysed according to different oxygenation index grades and prognosis, and factors influencing prognosis and survival were examined. Adolescent patients, patients with typical immunodeficiency and patients who died within $24 \mathrm{~h}$ after being diagnosed with ARDS were excluded. The predictive value for mortality was determined by Cox proportional hazard analysis.
\end{abstract}

Results: In total, 201 patients who fulfilled the Berlin definition of ARDS were included. The severity of critical illness on the day of enrolment, as measured by the Acute Physiology and Chronic Health Evaluation (APACHE) II score $(P=0.016)$, Sequential Organ Failure Assessment (SOFA) score $(P=0.027)$, and $\mathrm{PaO}_{2} / \mathrm{FiO}_{2}(P=0.000)$, worsened from mild to severe ARDS cases. Compared with survivors, non-survivors were significantly older and had higher APACHE II and SOFA scores. Moreover, significantly lower lymphocyte/neutrophil ratios and leukocyte counts were found among non-survivors than survivors $(P=0.008, P=0.012)$. A moderate positive correlation between the lymphocyte/ neutrophil and $\mathrm{PaO}_{2} / \mathrm{FiO}_{2}$ ratios $(P=0.023)$ was observed. In predicting 100-day survival in patients with ARDS, the area under the curve (AUC) for the lymphocyte/neutrophil ratio was significantly higher than those for the $\mathrm{PaO}_{2} /$ $\mathrm{FiO}_{2}$ ratio alone, body mass index (BMI) alone, and the lymphocyte count alone $(P=0.0062,0.0001$, and 0.0154$)$. Age (per $\log _{10}$ years), BMI < 24, SOFA score, leukocyte count, and the lymphocyte/neutrophil ratio were independent predictors of 28-day mortality in ARDS patients. Additionally, ARDS patients with a lymphocyte/ neutrophil ratio $<0.0537$ had increased 28 -day mortality rates $(P=0.0283)$. Old age affected both 28-day and 100day mortality rates $(P=0.0064,0.0057)$.

(Continued on next page)

\footnotetext{
* Correspondence: luohonghuxi@csu.edu.cn

${ }^{1}$ Department of Pulmonary and Critical Care Medicine, The Second Xiangya

Hospital, Central South University, No.139 Renmin Road, Changsha 410011,

Hunan, China

${ }^{2}$ The Respiratory Disease Research Institute of Hunan Province; The

Respiratory Disease Diagnosis and Treatment Center of Hunan Province,

No.139 Renmin Road, Changsha 410011, Hunan, China

Full list of author information is available at the end of the article
}

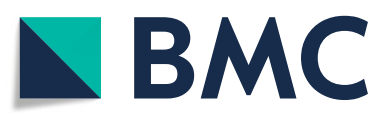

(c) The Author(s). 2020 Open Access This article is licensed under a Creative Commons Attribution 4.0 International License, which permits use, sharing, adaptation, distribution and reproduction in any medium or format, as long as you give appropriate credit to the original author(s) and the source, provide a link to the Creative Commons licence, and indicate if changes were made. The images or other third party material in this article are included in the article's Creative Commons licence, unless indicated otherwise in a credit line to the material. If material is not included in the article's Creative Commons licence and your intended use is not permitted by statutory regulation or exceeds the permitted use, you will need to obtain permission directly from the copyright holder. To view a copy of this licence, visit http://creativecommons.org/licenses/by/4.0/. The Creative Commons Public Domain Dedication waiver (http://creativecommons.org/publicdomain/zero/1.0/) applies to the data made available in this article, unless otherwise stated in a credit line to the data. 
(Continued from previous page)

Conclusions: Age (per $\log _{10}$ years), BMI < 24, SOFA score, lymphocytes, and the lymphocyte/neutrophil ratio were independent predictors of 100-day mortality in patients with ARDS. The lymphocyte/neutrophil ratio may represent a potential molecular marker to evaluate atypical immunosuppression or impairment in patients with ARDS.

Keywords: Acute respiratory distress syndrome, Morbidity, Outcome assessment, Prognostic

\section{Background}

Acute respiratory distress syndrome (ARDS) is a lifethreatening respiratory disease with a high mortality rate in critically ill patients $[1,2]$. Although many in-depth studies on ARDS have been conducted, the specific pathogenesis and prognostic factors of the disease remain unclear. Indeed, despite improvements in ventilatory techniques and extensive research to date, ARDS continues to be associated with high mortality [3, 4].

Nonetheless, clinical and animal studies have shown that the activation of multiple inflammatory cells and the release of inflammatory mediators play important roles in the development and outcome of ARDS [5]. The involvement of immune cells, including neutrophils [6, 7] lymphocytes [8], and regulatory T-cell [9, 10], has become an active topic of research in ARDS pathogenesis. To date, few clinical studies on the immune status of ARDS patients have focused on aetiology, treatment and prognosis [11]. Immunocompromised individuals represent a significant proportion of ARDS patients [11, 12], these patients do not have the ability to respond normally to an infection due to an impaired or weakened immune system. Some studies have shown that ARDS occurs in patients with previous immunodeficiencies, such as haematologic malignancies, active solid tumours, solid organ transplantation, and acquired immunodeficiency syndrome, as well as in patients taking long-term or high-dose corticosteroids or immunosuppressants, and those who use extra-corporeal membrane oxygenation (ECMO) may have a better prognosis [13]. Compared with immunocompetent subjects, ARDS patients with typical immunodeficiency have higher mortality regardless of ARDS severity [11]. In addition, atypical immunosuppression is frequently found among ARDS patients, and virus infections are also increasingly being reported in ARDS patients without typical immunosuppression [13]. Overall, there is currently a lack of uniform molecular markers for patients with atypical immunosuppression or impaired status. Furthermore, it is not well known whether the status of atypical immunodeficiency affects the prognosis of ARDS. Managing patients with atypical immunosuppression in intensive care unit (ICU) can be challenging, updated epidemiological and outcomes studies are needed to evaluate the condition of these patients.
This aim of our study was to identify a convenient and easy-to-use molecular biomarker to detect and evaluate the status of patients with atypical immunosuppression in ARDS patients.

\section{Methods}

\section{Study design and patients}

This retrospective observational cohort study was conducted with ARDS patients hospitalized in the critical care centre of a university-based tertiary care hospital (The Second Xiangya Hospital of Central South University) in Hunan, China, from January 2011 to August 2018. Institutional approval was provided by the Second Xiangya Hospital of Central South University Biomedical Research Ethics Committee (Hunan, China). Written informed consent was waived because of the retrospective observational design. All patient data were anonymously recorded to ensure confidentiality.

\section{Inclusion and exclusion criteria}

Patients admitted to the critical care centre with a diagnosis of ARDS based on the 2012 Berlin definition [14] were included in our study if they met the inclusion criteria and none of the exclusion criteria. All eligible patients were over 18 years old with available neutrophil and lymphocyte count results within $24 \mathrm{~h}$ after ICU admission. Patients who were repeatedly admitted to the ICU, lack of neutrophil and lymphocyte records, had chronic haematological disorders, were under the age of 18 years, or died within $24 \mathrm{~h}$ of receiving a diagnosis of ARDS were excluded. In addition, we excluded patients who were defined as having an immunodeficiency with the following aetiologies: (1) haematological malignancies, (2) active solid tumours or specific anti-tumour treatment within a year, (3) solid organ transplant, (4) acquired immunodeficiency syndrome (AIDS), or (5) long-term or high-dose corticosteroid (CS) or immunosuppressant (IS) therapy. Long-term CS therapy was defined as $>7.5 \mathrm{mg}$ of prednisone/day for $>3$ months, and a high dose was defined as $>1 \mathrm{mg} / \mathrm{kg}$ for $>1$ week within the previous 3 months. According to the $\mathrm{PaO}_{2} / \mathrm{FiO}_{2}$ ratio, patients were categorized as mild $\left(200 \mathrm{mmHg}<\mathrm{PaO}_{2} /\right.$ $\left.\mathrm{FiO}_{2} \leq 300 \mathrm{mmHg}, n=31\right)$, moderate $\left(100 \mathrm{mmHg}<\mathrm{PaO}_{2} /\right.$ $\left.\mathrm{FiO}_{2} \leq 200 \mathrm{mmHg}, n=61\right)$, and severe $\left(\mathrm{PaO}_{2} / \mathrm{FiO}_{2} \leq 100\right.$ mmHg, $n=109$ ) groups. In addition, 201 patients were included and divided into a survivor group $(n=80)$ and 
a non-survivor group $(n=121)$ according to the final clinical results.

\section{Data extraction and outcome}

Demographic and baseline characteristics such as age, sex, body mass index (BMI), ARDS risk factors, severity of illness upon admission to the ICU (Acute Physiology and Chronic Health Evaluation (APACHE) II score) [15], and the Sequential Organ Failure Assessment (SOFA) score [16] were recorded and analysed. We recorded routine blood examination results within $24 \mathrm{~h}$ and within 3 days after ICU admission. Two authors completed the data collection independently. The primary outcome was mortality, and the secondary outcomes were ICU mortality and hospital mortality. We also calculated 28-day mortality and 100-day mortality rates.

\section{Blood measurements and flow cytometric analysis} The white blood cell count, C-reactive protein (CRP) level and procalcitonin (PCT) level were measured. Serum levels of haemoglobin, albumin, immunoglobulins (IgG, IgA, IgM, IgE), and complement components (C3, C4) (R\&D Systems, USA) was determined by enzymelinked immunosorbent assay (ELISAs) in accordance with the manufacturer's instructions. To analyse Tlymphocytes, cell staining kit (BD ingen ${ }^{\mathrm{Tm}}$, USA) was used to detect $\mathrm{CD} 4+\mathrm{CD} 8+\mathrm{CD} 3+$ cells according to the manufacturer's protocol. Briefly, peripheral blood mononuclear cells (PBMCs) were incubated with a mixture of luciferin isothiocyanate anti-CD4 and apc anti-CD8 at $4{ }^{\circ} \mathrm{C}$ for $30 \mathrm{~min}$. Facscalibur flow cytometry (BD Biosciences, USA) and CellQuest software (BD Biosciences, USA) were used for flow cytometry analysis. A homotype control was used to ensure antibody specificity [17, $18]$.

\section{Statistical analysis}

We used the Kolmogorov-Smirnov test to assess distribution normality. The continuous variables were reported as the mean $\pm \mathrm{SD}$ or median (IQR). An independent samples t-test was used to evaluate normally distributed data, and the Mann-Whitney test was employed to evaluate non-normally distributed data when comparing two groups. In multi-group comparisons, one-way ANOVA and Kruskal-Wallis test were used to analyze the normal and non-normal distribution data respectively, and the $P$-values adjusted by Bonferroni were used for multiple groups of comparison. Classification data number (percentage) aggregation, and Chi-square or Fisher's exact test. Spearman's rank correlation was adopted to determine correlations among variables. Area under the curve operating characteristic (ROC) was used to evaluate the prognostic value of the subject properties, diagnostic and test parameters. The cut-off point was obtained by determining the optimal den index (sensitivity+specificity-1). We used KaplanMeier plots and log-rank tests to compare the survival rate of each group. To calculate an independent predictor of mortality of 100 days, with a stepwise binary logistic regression variables for the regression values of $P<0.05$ (one variable was entered when $\mathrm{P}<0.05$, and one was deleted when $P>0.10$ ). The odds ratio (OR), $P$ value and $95 \%$ CI were used to represent results. All tests were double-tailed, and $\mathrm{P}<0.05$ was considered statistically significant. All analyses were performeded using IBM SPSS 22.0 and MedCalc v.11.0.

\section{Results}

Baseline characteristics and patient outcome

A total of 201 patients meeting the Berlin definition of ARDS from January 2011 to August 2018 were included in this study. Characteristics at enrolment and outcomes of the study population are shown in Table 1 and Table 2. There were no statistically significant differences in age, sex or BMI among the mild, moderate and severe ARDS groups. The most common aetiologies of ARDS were pneumonia, sepsis and pancreatitis. According to the APACHE II score $(P=0.016)$, SOFA score $(P=0.027)$, and $\mathrm{PaO}_{2} / \mathrm{FiO}_{2}$ $(P=0.000)$, it can be seen that the severity of critical illness on the day of enrolment worsened from mild to severe ARDS, as shown in Tables 1 and 2. The 100-day mortality rate for patients with ARDS was $60.2 \%(121 / 201)$. Compared to non-survivors, the survivors were significantly younger, with relatively low scores for APACHE II and SOFA. Survivors had higher BMIs and $\mathrm{PaO}_{2} / \mathrm{FiO}_{2}$ ratios than did nonsurvivors.

\section{Correlations of the lymphocyte/neutrophil ratio with disease severity and outcome}

Compared with the mild group, the frequencies of lymphocyte cells were decreased in severe ARDS patients $(P=0.025)$. Moreover, the lymphocyte/neutrophil ratio decreased progressively with increasing ARDS severity $(P=0.001)$. Among non-survivors, a significantly lower lymphocyte/neutrophil ratio was found compared with that of survivors $(P=0.008)$ (Table 2), the frequencies of lymphocyte cells were lower than those in survivors $(\mathrm{P}=0.025)$ (Table 2), and the frequencies of leukocytes and neutrophil cells were both higher than those in survivors $(P=0.012$, 0.016) (Table 2). There were no significant differences among the three severity groups in terms of the frequencies of leukocytes and neutrophils (Table 1). 
Table 1 Baseline characteristics of the enrolled study population. Normally distributed quantitative data are expressed as means \pm standard deviation. Non-normally distributed quantitative data are expressed as medians (IQR)

\begin{tabular}{|c|c|c|c|c|c|}
\hline \multirow[t]{2}{*}{ Variables } & \multicolumn{2}{|c|}{ Acute respiratory distress syndrome } & \multirow[b]{2}{*}{ Moderate } & \multirow[b]{2}{*}{ Severe } & \multirow{2}{*}{$\begin{array}{l}\Delta \mathrm{P}_{-} \\
\text {value }\end{array}$} \\
\hline & Total & Mild & & & \\
\hline Number & 201 & 31 & 61 & 109 & \\
\hline Age,years & $54.24 \pm 16.35$ & $55.38 \pm 15.60$ & $52.43 \pm$ & $54.93 \pm 16.03$ & 0.579 \\
\hline Sex,male/female,n & $130 / 71$ & 19:12 & $40 / 21$ & $71 / 38$ & 0.415 \\
\hline $\mathrm{BMl}, \mathrm{kg} / \mathrm{m}^{2}$ & $23.90 \pm 3.82$ & $24.22 \pm 3.93$ & $23.83 \pm 4.05$ & $23.90 \pm 3.82$ & 0.896 \\
\hline \multicolumn{6}{|l|}{ Cause of ARDS } \\
\hline Pneumonia & 125 & 19 & 37 & 69 & \\
\hline Non-pulmonary spesis & 38 & 6 & 15 & 17 & \\
\hline Pancreatitis & 15 & 4 & 7 & 4 & \\
\hline Trauma & 7 & 0 & 0 & 7 & \\
\hline Aspiration & 2 & 0 & 0 & 2 & \\
\hline Others & 14 & 2 & 2 & 10 & \\
\hline APACHE II score & $14.19(7.69$ to 31.00$)$ & $12.74(7.69$ to 24.37$)$ & 14.52 (9.86 to 27.69 ) & $14.34(9.68 \text { to } 31.00)^{*}$ & 0.016 \\
\hline SOFA score & $4.98(4.65$ to 5.30$)$ & $4.59(3.97$ to 5.20$)$ & 5.11 (4.71 to 5.53 ) & 5.26 (4.89 to 5.63$)$ & 0.027 \\
\hline $\mathrm{PaO}_{2} / \mathrm{FiO}_{2}, \mathrm{mmHg}$ & $123(112$ to 134$)$ & 280 (267 to 294) & $140(132 \text { to } 146)^{*}$ & $69(65 \text { to } 72)^{* \#}$ & 0.000 \\
\hline $\mathrm{CRP}, \mathrm{mg} / \mathrm{L}$ & $\begin{array}{l}129.82 \text { (129.82 to } \\
169.91)\end{array}$ & $\begin{array}{l}110.09 \text { (76.59 to } \\
143.59 \text { ) }\end{array}$ & $\begin{array}{l}163.90(138.67 \text { to } \\
189.14)^{*}\end{array}$ & $\begin{array}{l}203.33(115.97 \text { to } \\
290.68)^{*}\end{array}$ & 0.011 \\
\hline $\mathrm{PCT}, \mathrm{ng} / \mathrm{ml}$ & $12.20(8.12$ to 16.29$)$ & 9.37 (5.45 to 13.30$)$ & 10.15 (1.51 to 18.80$)$ & $17.05(7.58 \text { to } 27.73)^{*}$ & 0.175 \\
\hline Albumin,g/L & $27.67 \pm 5.82$ & $27.13 \pm 3.17$ & $27.07 \pm 6.05$ & $28.10 \pm 6.05^{*}$ & 0.759 \\
\hline Hemoglobin,g/L & $107.67 \pm 28.32$ & $104.04 \pm 23.76$ & $107.29 \pm 28.05$ & $108.82 \pm 29.73$ & 0.759 \\
\hline Leukocytes, $10^{9} / \mathrm{L}$ & $11.33(10.12$ to 12.54$)$ & 10.98 (8.67 to 13.28 ) & 10.91 (9.62 to 12.22 ) & 13.65 (8.65 to 18.64$)$ & 0.298 \\
\hline Lymphocytes, $10^{9} / \mathrm{L}$ & $1.10(0.95$ to 1.26$)$ & 1.28 (0.86 to 1.75$)$ & 1.10 (8.67 to 13.28$)$ & $1.07(0.87 \text { to } 1.27)^{*}$ & 0.025 \\
\hline Neutrophils, $10^{9} / \mathrm{L}$ & 10.78 (8.38 to 13.18$)$ & 8.35 (6.91 to 9.78$)$ & 11.66 (7.59 to 15.74$)$ & 13.03 (7.31 to 18.76$)$ & 0.371 \\
\hline Lymphocyte/Neutrophil ratio & $0.19 \pm 0.03$ & $0.35 \pm 0.23$ & $0.17 \pm 0.03^{*}$ & $0.15 \pm 0.02^{*}$ & 0.001 \\
\hline Virus infection,n, $\%$ & $23(11.44 \%)$ & $1(3.23 \%)$ & 10(16.39\%) & $12(11.0 \%)$ & \\
\hline 28-day mortality,n,\% & $103(51.24 \%)$ & $13(41.94 \%)$ & $31(50.82 \%)$ & $59(54.13 \%)$ & \\
\hline 100-day mortality,n, $\%$ & $121(60.20 \%)$ & $15(48.39 \%)$ & $37(60.66 \%)$ & $69(63.30 \%)$ & \\
\hline \multicolumn{6}{|l|}{ Immunoglobulin } \\
\hline $\lg G, g / L$ & $10.87 \pm 1.86$ & $11.71 \pm 4.96$ & $10.82 \pm 1.94$ & $10.59 \pm 5.36$ & 0.095 \\
\hline $\lg A, g / L$ & $1.98 \pm 0.24$ & $1.92 \pm 1.09$ & $1.85 \pm 0.72$ & $2.11 \pm 1.40$ & 0.270 \\
\hline $\operatorname{lgM}, g / L$ & $1.05 \pm 0.86$ & $1.32 \pm 1.18$ & $1.02 \pm 0.92$ & $1.00 \pm 0.72$ & 0.598 \\
\hline $\lg \mathrm{E}, \mathrm{ng} / \mathrm{mL}$ & $620.36 \pm 145.11$ & $1426.20 \pm 119.89$ & $640.55 \pm 32.45$ & $356.87 \pm 78.73^{*}$ & 0.025 \\
\hline \multicolumn{6}{|l|}{ Complement components } \\
\hline $\mathrm{C} 3$ & $5.62 \pm 1.78$ & $12.27 \pm 1.83$ & $7.13 \pm 3.14$ & $0.84 \pm 0.33^{*}$ & 0.186 \\
\hline C4 & $1.33 \pm 0.58$ & $0.25 \pm 0.13$ & $0.24 \pm 0.11$ & $2.25 \pm 0.95^{*}$ & 0.663 \\
\hline \multicolumn{6}{|l|}{ T-lymphocytes subsets } \\
\hline CD3+ cells, $\%$ & $62.75 \pm 15.29$ & $71.00 \pm 13.78$ & $63.35 \pm 12.44$ & $60.62 \pm 17.11$ & 0.229 \\
\hline CD4+ cells, $\%$ & $35.15 \pm 15.48$ & $36.40 \pm 13.69$ & $34.10 \pm 11.14$ & $35.66 \pm 8.47$ & 0.951 \\
\hline CD4+ cells count (PCS/ul) & $383.20 \pm 67.18$ & $176.50 \pm 67.18$ & $383.67 \pm 94.79$ & $434.08 \pm 78.66$ & 0.708 \\
\hline CD8+ cells, $\%$ & $27.33 \pm 13.46$ & $34.33 \pm 6.37$ & $25.60 \pm 11.59$ & $26.92 \pm 14.01$ & 0.275 \\
\hline CD8+ cells count (PCS/ul) & $212.33 \pm 64.30$ & $134.00 \pm 30.63$ & $286.67 \pm 51.72$ & $178.91 \pm 70.96$ & 0.409 \\
\hline CD4+/CD8+ ratio & $1.95 \pm 0.26$ & $1.29 \pm 0.23$ & $1.91 \pm 0.93$ & $2.14 \pm 0.48$ & 0.623 \\
\hline
\end{tabular}

B-lymphocytes 
Table 1 Baseline characteristics of the enrolled study population. Normally distributed quantitative data are expressed as means \pm standard deviation. Non-normally distributed quantitative data are expressed as medians (IQR) (Continued)

\begin{tabular}{|c|c|c|c|c|c|}
\hline \multirow[t]{2}{*}{ Variables } & \multicolumn{2}{|c|}{ Acute respiratory distress syndrome } & \multirow[b]{2}{*}{ Moderate } & \multirow[b]{2}{*}{ Severe } & \multirow{2}{*}{$\begin{array}{l}\Delta \mathrm{p}_{-} \\
\text {value }\end{array}$} \\
\hline & Total & Mild & & & \\
\hline B-lymphocytes, $\%$ & $30.25 \pm 17.28$ & $18.00 \pm 3.24$ & $26.20 \pm 7.81$ & $33.36 \pm 7.81$ & 0.598 \\
\hline $\begin{array}{l}\text { B-lymphocytes cell count (PCS/ } \\
\mu \text { l) }\end{array}$ & $301.05 \pm 73.77$ & $69.01 \pm 8.89$ & $413.20 \pm 41.42$ & $271.18 \pm 78.37$ & 0.665 \\
\hline \multicolumn{6}{|l|}{ NK cell } \\
\hline NK cells, $\%$ & $8.76 \pm 5.91$ & $17.00 \pm 4.41$ & $9.40 \pm 0.81$ & $7.73 \pm 4.58$ & 0.331 \\
\hline NK cell count (PCS/ul) & $68.77 \pm 46.46$ & $68.20 \pm 7.66$ & $82.60 \pm 14.82$ & $62.55 \pm 15.15$ & 0.751 \\
\hline
\end{tabular}

Qualitative data are presented as numbers (\%). ${ }^{\triangle} P$-value for the three groups (mild, moderate, and severe ARDS groups); ${ }^{*} P<0.05$ versus mild ARDS; ${ }^{\#} P<0.05$ versus moderate ARDS. BMI body mass index, APACHE Acute Physiology and Chronic Health Evaluation SOFA Sequential Organ Failure Assessment, CRP C-reactive protein, $P C T$ procalcitonin

\section{Alterations in inflammatory biomarkers, immunoglobulins, complement components, circulating T-lymphocyte cells, B-lymphocyte cells and NK cells in ARDS}

CRP levels progressively increased with increasing ARDS severity $(P=0.011)$. The PCT level of patients with severe ARDS was higher than that of patients with mild ARDS $(P=0.002)$. Interestingly, the lymphocyte count decreased as the severity of ARDS increased $(P=0.025)$ (Table 1$)$. In addition, compared with survivors, non-survivors were older $(P=0.004)$, and had higher leukocyte and neutrophil counts $(P=$ $0.012,0.016)$ and lower BMI, lymphocyte counts and lymphocyte/neutrophil ratios $(P=0.027,0.025$, and 0.008) (Table 2). CRP and PCT levels in the two groups were similar (Table 2).

The peripheral blood immunoglobulin IgE and complement C3 levels in patients with mild ARDS were significantly higher than those in patients with severe ARDS $(P=0.023,0.019)$. Moreover, the levels of immunoglobulin IgE and complement C3 in nonsurvivors were lower than in survivors $(P=0.009$, 0.018) (Table 2). Peripheral blood complement C4 levels in patients with mild ARDS were significantly lower than those in patients with severe ARDS $(P=$ 0.026) (Table 1), but the level of complement $C 4$ was similar between survivors and non-survivors (Table 2).

The level of peripheral blood B-lymphocyte cells was significantly lower in non-survivors than in survivors $(\mathrm{P}=0.009)$, as was the level of peripheral blood CD8+ cells $(P=0.024)$, though the levels of both peripheral blood B-lymphocyte cells and CD8+ cells were similar in the three groups (Table 1). In addition, the proportions of CD3+ cells, CD4+ cells, and NK cells and the CD4+/ CD8+ ratio in peripheral blood showed no significant differences among the three groups of ARDS patients stratified by oxygenation index or between the survivor and non-survivor groups.
Correlations of lymphocytes, the lymphocyte/neutrophil ratio, immunoglobulin IgE levels, complement $\mathrm{C} 3$ levels, T-CD8+ lymphocyte levels and B-lymphocyte levels with disease severity and outcome

We noted that in all ARDS patients, the lymphocyte/ neutrophil ratio was moderately negatively correlated with age $(r=-0.153, P=0.030$, Fig.1a), SOFA score $(r=$ $-0.140, P=0.038$, Fig.1b), and the APACHE II score ( $\mathrm{r}=-0.177, P=0.012$, Fig.1c). We also observed that, there is a moderate positive correlation between the lymphocyte/neutrophil ratio and $\mathrm{PaO}_{2} / \mathrm{FiO}_{2}$ ratio $(\mathrm{r}=$ $0.143, P=0.023$, Fig.1d). Moreover, significant mild positive correlations were found between the lymphocyte count and BMI $(\mathrm{r}=0.145, P=0.041)$, the lymphocyte count and the $\mathrm{PaO}_{2} / \mathrm{FiO}_{2}$ ratio $(\mathrm{r}=0.110, P=0.121)$, the immunoglobulin IgE level and the $\mathrm{PaO}_{2} / \mathrm{FiO}_{2}$ ratio $(\mathrm{r}=$ $0.288, P=0.036)$, the C3 level and BMI $(r=0.342, P=$ $0.026)$, the T-CD8+ lymphocyte count and the lymphocyte count ( $r=0.755, P=0.001)$, the B-lymphocyte count and BMI $(r=0.588, P=0.013)$, and the B-lymphocyte cell count and lymphocyte count $(\mathrm{r}=0.582, P=0.014)$.

The area under the ROC curve (AUC) for the lymphocyte/neutrophil ratio for the prediction of 100-day survival in ARDS patients was 0.721 (95\% CI 0.653 to 0.782 ) and was significantly higher than the AUC for the $\mathrm{PaO}_{2} / \mathrm{FiO}_{2}$ ratio alone $(0.625,95 \% \mathrm{CI} 0.554$ to 0.692 , $P=0.0062$,), the AUC for BMI alone $(0.593,95 \% \mathrm{CI}$ 0.521 to $0.661, P=0.0001)$ or the AUC for the lymphocyte count alone $(0.592,95 \%$ CI 0.520 to $0.660, P=$ 0.0154) (Fig.2). The AUC for the lymphocyte/neutrophil ratio in combination with the lymphocyte count for the prediction of 100-day survival in ARDS patients was 0.723 (95\% CI 0.656 to 0.784 ), which was larger than both the AUC for the lymphocyte/neutrophil ratio alone $(P=0.8601)$ and the lymphocyte/neutrophil ratio in combination with the $\mathrm{PaO}_{2} / \mathrm{FiO}_{2}$ ratio $(0.719,95 \% \mathrm{CI}$ 0.651 to $0.780, P=0.7734$ ) (Fig.2). In predicting survival in patients with ARDS, the AUC for the lymphocyte/ neutrophil ratio in combination with the lymphocyte 
Table 2 Comparison of clinical characteristics of ARDS patients according to survival status. Normally distributed quantitative data are expressed as means \pm standard deviation. Non-normally distributed quantitative data are expressed as medians (IQR)

\begin{tabular}{|c|c|c|c|}
\hline Variables & Non-survivors $(\boldsymbol{n}=121)$ & Survivors $(\boldsymbol{n}=80)$ & $\boldsymbol{P}$-value \\
\hline Age,years & $56.96 \pm 17.09$ & $50.16 \pm 14.33$ & 0.004 \\
\hline Sex,male/female,n & $76 / 45$ & $54 / 26$ & 0.496 \\
\hline $\mathrm{BMI}, \mathrm{kg} / \mathrm{m}^{2}$ & $23.41 \pm 3.88$ & $24.69 \pm 3.93$ & 0.027 \\
\hline APACHE I| score & $14.96(14$ to 16$)$ & 13.51 (13 to 15$)$ & 0.036 \\
\hline SOFA score & $5.42(5$ to 6$)$ & 4.15 (4 to 5 ) & 0.000 \\
\hline $\mathrm{PaO}_{2} / \mathrm{FiO}_{2}, \mathrm{mmHg}$ & 115 (102 to 188$)$ & 135 (115 to 154$)$ & 0.042 \\
\hline $\mathrm{CRP}, \mathrm{mg} / \mathrm{L}$ & 152.20 (126.50 to 177.89$)$ & $146.32(113.27$ to 179.37$)$ & 0.778 \\
\hline $\mathrm{PCT}, \mathrm{ng} / \mathrm{Ml}$ & 13.67 (5.49 to 21.89) & $11.30(6.90$ to 15.70$)$ & 0.577 \\
\hline Hemoglobin,g/L & $105.63 \pm 27.68$ & $110.41 \pm 30.74$ & 0.298 \\
\hline Albumin,g/L & $27.24 \pm 5.68$ & $28.33 \pm 6.02$ & 0.223 \\
\hline Leukocytes, $10^{9} / \mathrm{L}$ & 12.19 (10.41 to 13.97$)$ & 10.80 (9.47 to 12.14$)$ & 0.012 \\
\hline Lymphocytes, $10^{9} / \mathrm{L}$ & 1.03 (0.86 to 1.20 & $1.21(0.92$ to 1.50$)$ & 0.025 \\
\hline Neotrophils, $10^{9} / \mathrm{L}$ & 9.80 (8.29 to 11.31$)$ & 8.80 (7.64 to 9.95$)$ & 0.016 \\
\hline Lymphocyte/Neotrophil ratio & $0.15 \pm 0.05$ & $0.20 \pm 0.28$ & 0.008 \\
\hline Virus infection & 12(9.91\%) & $11(13.75 \%)$ & \\
\hline \multicolumn{4}{|l|}{ Immunoglobulin } \\
\hline $\lg G, g / L$ & $9.95 \pm 2.37$ & $12.42 \pm 3.88$ & 0.169 \\
\hline $\lg A, g / L$ & $1.80 \pm 0.53$ & $2.29 \pm 1.04$ & 0.156 \\
\hline $\lg M, g / L$ & $0.90 \pm 0.25$ & $1.22 \pm 0.33$ & 0.163 \\
\hline $\operatorname{lgE}, \mathrm{ng} / \mathrm{mL}$ & $351.97 \pm 80.27$ & $1030.29 \pm 220.94$ & 0.009 \\
\hline \multicolumn{4}{|l|}{ Complement component } \\
\hline C3 & $3.27 \pm 0.91$ & $10.31 \pm 2.06$ & 0.018 \\
\hline C4 & $1.84 \pm 0.46$ & $0.25 \pm 0.10$ & 0.170 \\
\hline \multicolumn{4}{|l|}{ T-lymphocyte subsets } \\
\hline CD3+ cells, $\%$ & $61.90 \pm 15.49$ & $63.83 \pm 15.29$ & 0.647 \\
\hline CD4+ cells, $\%$ & $33.93 \pm 16.06$ & $36.67 \pm 14.93$ & 0.521 \\
\hline CD4+ cell count $(\mathrm{PCS} / \mu \mathrm{l})$ & $328.85 \pm 72.23$ & $487.86 \pm 65.04$ & 0.512 \\
\hline CD8+ cells, $\%$ & $29.47 \pm 5.42$ & $24.38 \pm 9.75$ & 0.190 \\
\hline CD8+ cell count $(\mathrm{PCS} / \mu \mathrm{l})$ & $152.75 \pm 22.66$ & $331.50 \pm 95.71$ & 0.024 \\
\hline CD4+/CD8+ ratio & $1.79 \pm 0.09$ & $1.78 \pm 0.12$ & 0.428 \\
\hline \multicolumn{4}{|l|}{ B-lymphocytes } \\
\hline B-lymphocyte cells, $\%$ & $29.81 \pm 8.89$ & $31.33 \pm 5.49$ & 0.169 \\
\hline B-lymphocyte cell count (PCS/Ml) & $113.27 \pm 29.45$ & $601.33 \pm 52.26$ & 0.009 \\
\hline \multicolumn{4}{|l|}{ NK cell } \\
\hline NK cells, $\%$ & $9.19 \pm 3.28$ & $8.00 \pm 1.67$ & 0.708 \\
\hline NK cell count (PCS/Ml) & $56.55 \pm 12.87$ & $91.17 \pm 19.79$ & 0.134 \\
\hline
\end{tabular}

$B M I$ body mass index, APACHE Acute Physiology and Chronic Health Evaluation, SOFA Sequential Organ Failure Assessment, CRP,C-reactive protein, PCT procalcitonin

count was significantly higher than those for the $\mathrm{PaO}_{2} /$ $\mathrm{FiO}_{2}$ ratio alone $(P=0.0060)$, BMI alone $(P=0.0001)$, and lymphocyte count alone $(P=0.0067)$, and the AUC for the lymphocyte/neutrophil ratio in combination with the $\mathrm{PaO}_{2} / \mathrm{FiO}_{2}$ ratio was significantly higher than those for the $\mathrm{PaO}_{2} / \mathrm{FiO}_{2}$ ratio alone $(P=0.0014)$, BMI alone $(\mathrm{P}=0.0001)$, and lymphocytes alone $(P=0.0162)$.

A cut-off value of the lymphocyte/neutrocyte ratio of $>0.0537$ was used to predict the survival of ARDS patients. The sensitivity was $83.8 \%$, and the specificity was $80.2 \%$. The positive likelihood ratio was 4.23 , and the 

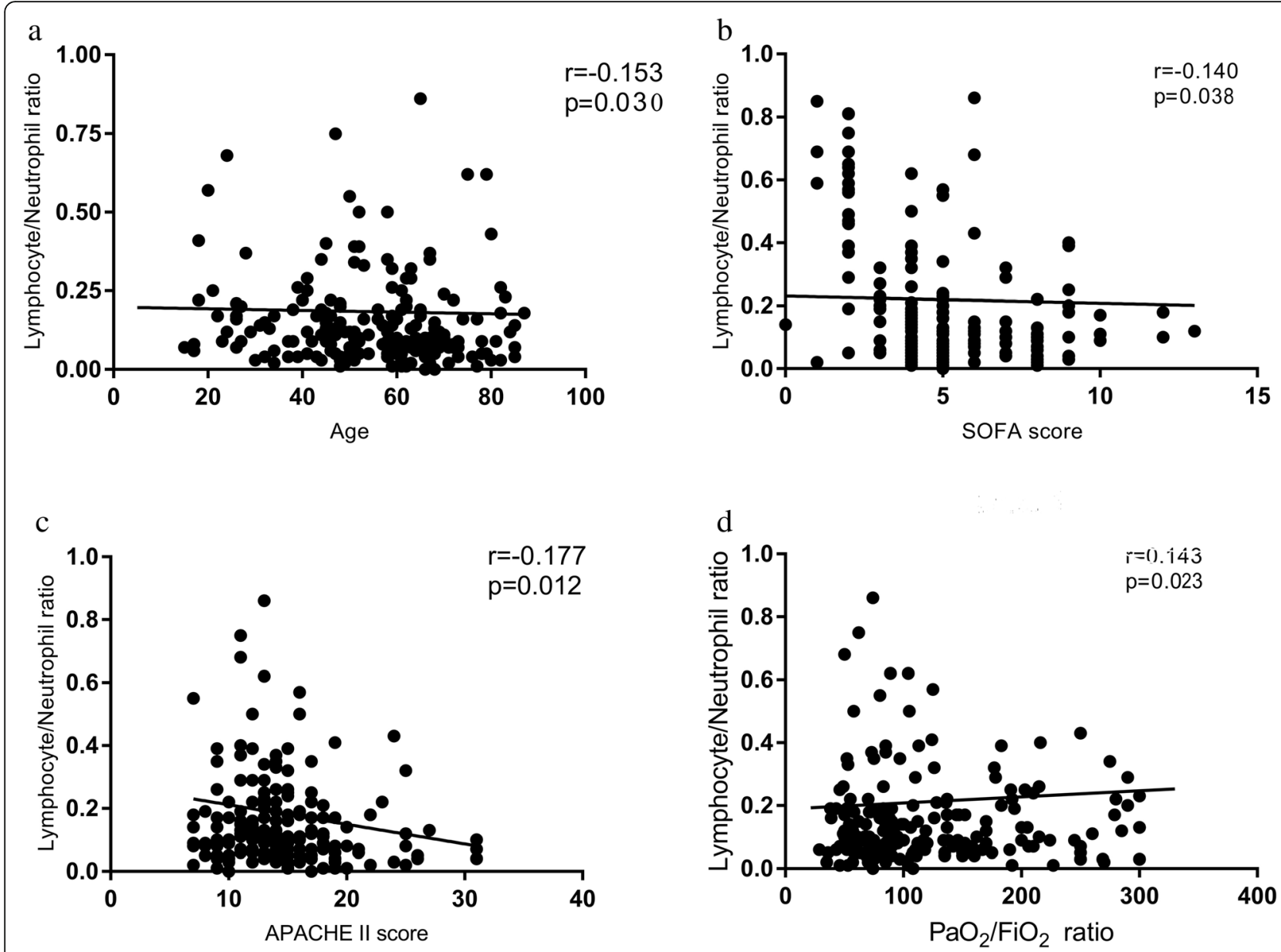

Fig. 1 Relationships between the lymphocyte/neutrophil ratio and age, APACHE II score, SOFA score, and $\mathrm{PaO}_{2} / \mathrm{FiO}_{2}$ ratio in ARDS patients. Spearman rank correlation was used to assess associations between variables. The lymphocyte/neutrophil ratio correlated negatively with age (a), the SOFA score (b), and the APACHE II score (c) but positively with the $\mathrm{PaO}_{2} / \mathrm{FiO}_{2}$ ratio (D) in ARDS patients

negative likelihood ratio was 0.20 . Moreover, a leukocyte count cut-off of $>0.415\left(10^{9} / \mathrm{L}\right)$ was used to predict the survival of patients with ARDS. The sensitivity was $87.5 \%$, and the specificity was $81.0 \%$. The positive likelihood ratio was 4.61, and the negative likelihood ratio was 0.15 .

Predictors of 28-day and 100-day mortality in patients with ARDS

Table 3 shows that age (per $\log _{10}$ years) $(\mathrm{OR}=1.269$, $P=0.019), \mathrm{BMI}<24(\mathrm{OR}=1.665, P=0.015)$, SOFA score $(\mathrm{OR}=1.287, P=0.002)$, leukocyte count $<0.415\left(10^{9} / \mathrm{L}\right)$ (OR $=1.671, P=0.042)$, and lymphocyte/neutrophil ratio $(\mathrm{OR}=2.132, P=0.009)$ were independent predictors of 100-day mortality in ARDS patients. Moreover, ARDS patients with a lymphocyte/neutrophil ratio $<0.0537$ had a higher 28-day mortality rate than did those with a lymphocyte/neutrophil ratio $>0.0537(P=0.0283$, Fig. 3a). Furthermore, 28-day and 100-day mortality rates were significantly lower in those under 40 years old and 40
60 years old than in those over 60 years old age $(P=$ $0.0064,0.0057$, Fig. 3b, c). The 100-day mortality rate was significantly higher in those over 80 years old than in those under 40 years old, 40-60 years old and 60-80 years old $(P=0.0029$, Fig. $3 \mathrm{~d})$.

\section{Discussion}

In this study, we found associations between age, BMI, the SOFA score, and the lymphocyte/neutrophil ratio at ICU admission and clinical outcomes in patients with ARDS. Age (per $\log _{10}$ years), BMI $<24$, the SOFA score (per point) and the lymphocyte/neutrophil ratio were independent risk factors for predicting 100-day mortality in ARDS patients. Another discovery was that the lymphocyte/neutrophil ratio and age were related to ICU mortality and hospital mortality. We also found associations between the baseline lymphocyte/neutrophil ratio and age, the SOFA score, the APACHE II score, the $\mathrm{PaO}_{2} / \mathrm{FiO}_{2}$ ratio, and the severity of ARDS according to the Berlin classification. The lymphocyte/neutrophil 


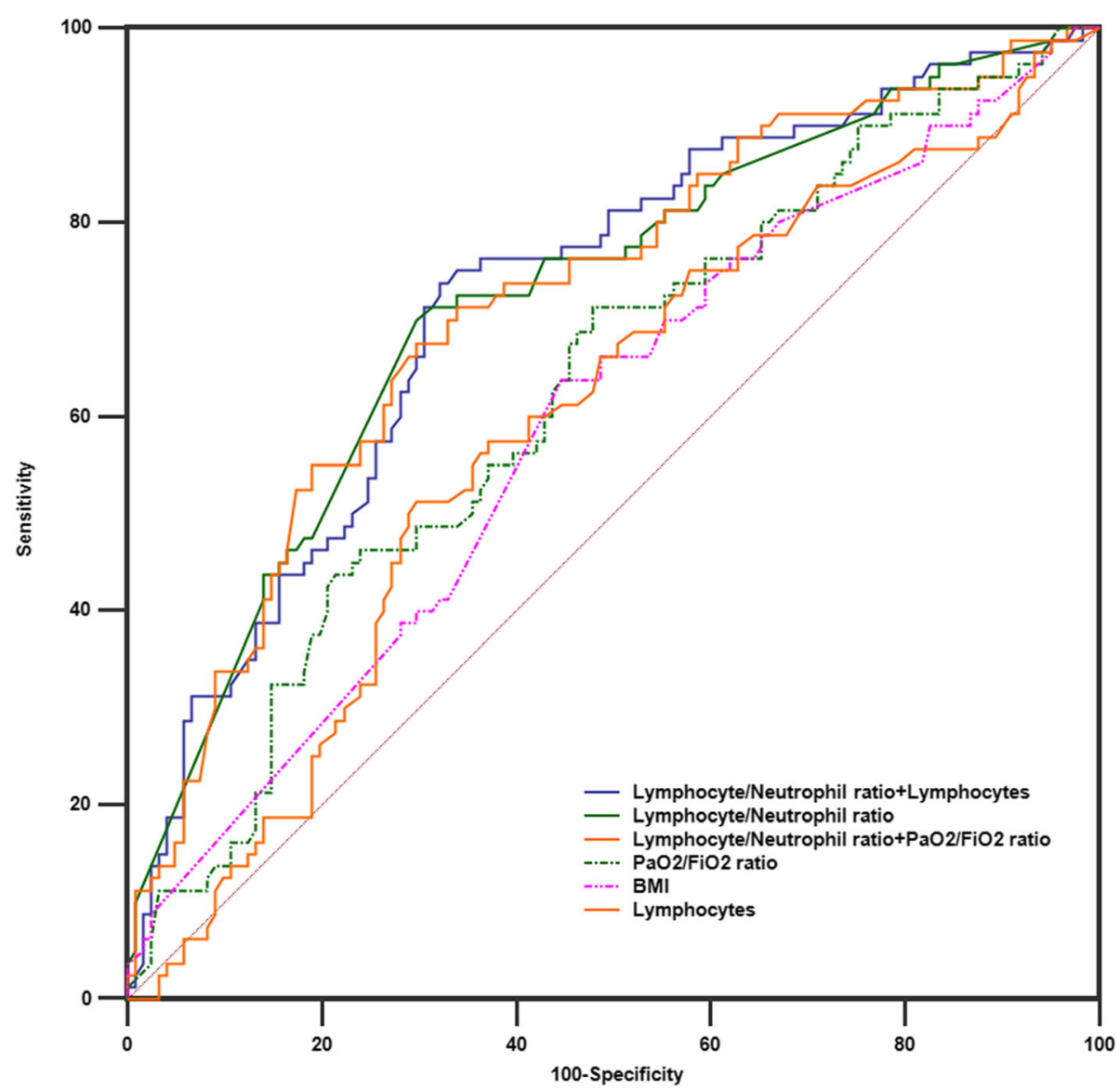

Fig. 2 Receiver operating characteristic (ROC) curves for predicting 100-day survival in patients with acute respiratory distress syndrome (ARDS). The area under the curve (AUC) was 0.721 ( $95 \% \mathrm{Cl} 0.656$ to 0.784$)$ for the lymphocyte/neutrophil ratio, $0.625(95 \% \mathrm{Cl} 0.554$ to 0.692$)$ for the $\mathrm{PaO} /$ $\mathrm{FiO}_{2}$ ratio, $0.593(95 \% \mathrm{Cl} 0.521$ to 0.661$)$ for the $\mathrm{BMI}, 0.592(95 \% \mathrm{Cl} 0.520$ to 0.660$)$ for the lymphocyte count, $0.723(95 \% \mathrm{Cl} 0.656$ to 0.784$)$ for the lymphocyte/neutrophil ratio combined with the lymphocyte count and 0.719 ( $95 \% \mathrm{Cl} 0.651$ to 0.780 ) for the lymphocyte/neutrophil ratio in combined with the $\mathrm{PaO}_{2} / \mathrm{FiO}_{2}$ ratio. The AUC was 0.369 ( $95 \% \mathrm{Cl} 0.292$ to 0.446$)$ for age, 0.425 ( $95 \% \mathrm{Cl} 0.345$ to 0.505$)$ for the APACHE II score, and 0.355 ( $95 \% \mathrm{Cl} 0.278$ to 0.433 ) for the SOFA score (not shown)

Table 3 Logistic regression analysis of the prediction of mortality for patients with acute respiratory distress syndrome (ARDS)

\begin{tabular}{|c|c|c|c|c|}
\hline \multirow[t]{2}{*}{ Variables } & \multicolumn{2}{|l|}{ Univariate analysis } & \multicolumn{2}{|l|}{ Multivariate analysis } \\
\hline & Odds ratio $(95 \% \mathrm{Cl})$ & $P$-value & Odds ratio $(95 \% \mathrm{Cl})$ & $P$-value \\
\hline Age,per $\log _{10}($ years $)$ & $1.269(1.040,1.548)$ & 0.019 & $2.982(2.073,4.654)$ & 0.007 \\
\hline $\mathrm{BMI}_{1}<24$ & $1.665(0.883,3.137)$ & 0.015 & & \\
\hline APACHE II score,per point & $1.016(0.940,1.098)$ & 0.059 & & \\
\hline SOFA score,per point & $1.287(1.098,1.509)$ & 0.002 & $2.560(1.457,5.430)$ & 0.005 \\
\hline $\mathrm{PaO}_{2} / \mathrm{FiO}_{2}$, per $\log _{10}(\mathrm{mmHg})$ & $0.652(0.280,1.004)$ & 0.067 & & \\
\hline PCT,per $\log _{10}(n g / m L)$ & $1.028(0.797,1.810)$ & 0.063 & & \\
\hline $\mathrm{CRP},>150(\mathrm{mg} / \mathrm{L})$ & $1.256(0.618,2.553)$ & 0.059 & & \\
\hline Lymphocytes, $<0.415 \times 10^{9} / \mathrm{L}$ & $1.671(1.252,1.787)$ & 0.042 & & \\
\hline Lymphocyte/Neutrophil ratio,<0.0537 & $4.137(1.452,6.832)$ & 0.002 & $3.726(2.754,5.195)$ & 0.003 \\
\hline
\end{tabular}

$B M I$ body mass index, APACHE Acute Physiology and Chronic Health Evaluation, SOFA Sequential Organ Failure Assessment, $P C T$ procalcitonin, CRP C-reactive protein 

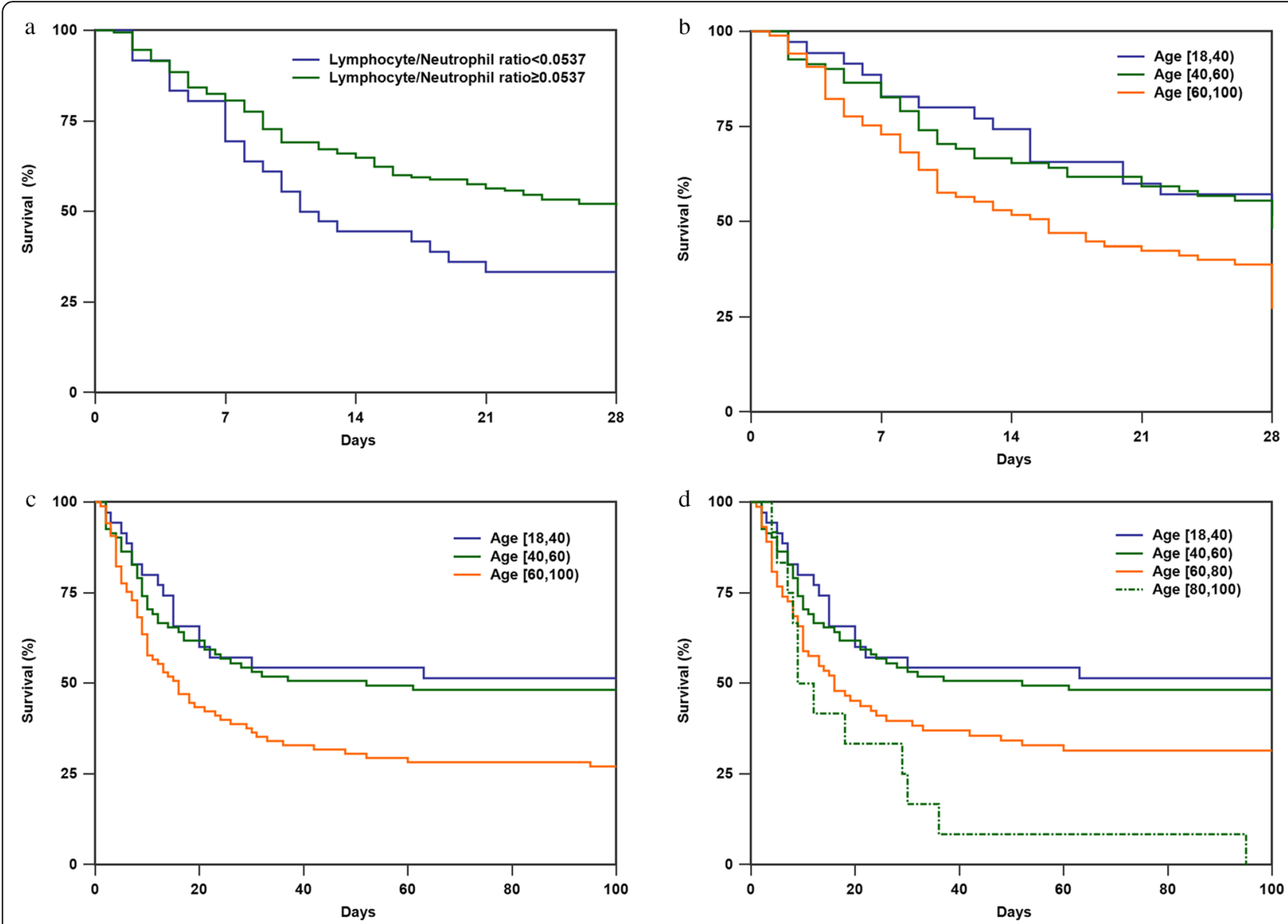

Fig. 3 Kaplan-Meier survival curve for patients with ARDS using the cut-off values for the lymphocyte/neutrophil ratio and age obtained by ROC analysis. Log-rank test $(P=0.0283)(\mathbf{a}),(P=0.0064)(\mathbf{b}),(P=0.0057)(\mathbf{c})$, and $(P=0.0029)(\mathbf{d})$

ratio may help predict prognosis for ARDS patients with a high immunologic risk. Our study is a longitudinal clinical outcome study of ARDS patients, and the results demonstrate the predictive significance of the lymphocyte/neutrophil ratio.

During the past decade, there have been a few investigations addressing the potential function of the lymphocyte/neutrophil ratio, which remains a useful test for the diagnosis of tuberculous pleuritis [19] and acts as an early biomarker for predicting acute rejection after heart transplantation [20]. Previous studies have focused on the poor prognosis of patients with severe lymphopenia from the first day of ICU admission [21]. In our study, peripheral blood lymphopenia was very common in ARDS patients without typical underlying diseases, causing immunosuppression. The number of peripheral blood lymphocytes decreased significantly in patients with severe ARDS, and in non-survivors also. Moreover, the lymphocyte/neutrophil ratio progressively decreased with increasing ARDS severity, and a significantly lower lymphocyte/neutrophil ratio was found in non-survivors than in survivors.
A decrease in the lymphocyte/neutrophil ratio is due to a decrease in the lymphocyte count and an increase in the neutrophil count. In our study, ARDS patients with a lymphocyte/neutrophil ratio $<0.0537$ had a higher 28-day mortality rate than did those with a lymphocyte/ neutrophil ratio $\geq 0.0537$. The lymphocyte/neutrophil ratio may reveal the balance between lymphocyte and neutrophil counts. Lymphocytes are important immune cells involved in response to ARDS and in prognosis. Multivariate analysis showed that a decrease in the lymphocyte count was associated with a 2.32-3.76-fold increase in the risk of death among patients with or without septic shock [22]. In addition, both B-lymphocyte and CD8 + T-lymphocyte counts correlated positively with peripheral blood lymphocyte counts in our study, these counts in non-survivors were significantly lower than those in survivors, and the findings suggest increased risk of death in ARDS patients when the lymphocyte count decreases below a certain value. Neutrophils are another type of immune cell involved in the process of sepsis, and a relative increase in the total number of circulating neutrophils and the percent increase in 
neutrophils with immature morphology are also closely related to sepsis [23, 24]. Compared with counts in survivors, higher neutrophil counts were found in patients who eventually died as a result of sepsis-induced ARDS, and excessive accumulation of neutrophils in patients with ARDS may therefore contribute to disease progression $[6,8]$. Therefore, the combination of lymphopenia and neutrophilia contributes to the outcome of ARDS, which may explain why the lymphocyte/neutrophil ratio in our study was a strong independent predictor of prognosis.

Although the clinical scores, such as APACHE II [25], SOFA [26] and the $\mathrm{PaO}_{2} / \mathrm{FiO}_{2}$ ratio [27], have been widely used to predict the results of clinical practice patients of ARDS. We further found that the lymphocyte/ neutrophil ratio AUC was higher than the $\mathrm{PaO}_{2} / \mathrm{FiO}_{2}$ ratio, BMI, APACHE II score, and SOFA score alone in predicting 100-day survival in ARDS patients. In combination with the lymphocyte count slightly increased the AUC of the lymphocyte/neutrophil ratio in predicting 100-day survival, yet there was no difference compared with the lymphocyte/neutrophil ratio alone. Moreover, ARDS patients with a lymphocyte/neutrophil ratio $\geq 0.0537$ had a lower 28 -day mortality rate, and significantly moderate negative correlations were found between the lymphocyte/neutrophil ratio and age, the SOFA score, and the APACHE II score. In addition, a moderate positive correlation between the lymphocyte/ neutrophil ratio and the $\mathrm{PaO}_{2} / \mathrm{FiO}_{2}$ ratio was been noted. These results suggest that the lymphocyte/neutrophil ratio can comprehensively and plausibly reflect the patient's physiological, pathophysiological and respiratory oxygenation index status. Taken together, our findings strongly suggest that the lymphocyte/neutrophil ratio is a potential indicator and good indicator for prognosis evaluation among ARDS patients.

There have been many clinical studies on ARDS patients with typical immunodeficiency [13, 28], and immunodeficiency in ARDS patients is usually atypical. Although it does not reach the level found in typical immunodeficiency, there is already a degree of immune impairment. Nonetheless, there are few studies on atypical immune deficiency or impaired immunity in ARDS patients, and there is no uniform scale or biomarker to measure immune impairment in ARDS patients and its relationship with prognosis. A consensus has not been reached regarding whether viral infection causes immune deficiency, though it is commonly thought to induce immune impairment but not to the extent of immune deficiency. In our study, there was no significant difference in viral infection status between the survivor and non-survivor groups. However, we did observe that the lymphocyte/neutrophil ratio in the survivor group were higher than those in the non-survivor group.
We hypothesize that a low lymphocyte/neutrophil ratio may be a marker of this atypical immunodeficiency in ARDS patients, affecting their prognosis. There are no recognized biomarkers to date that can be used to identify the immune status of ARDS patients. Accordingly, we propose a new biomarker for the identification of atypical immune status in patients with ARDS. This status may be due to abnormal inhibitors that have been be activated. We hope that by observing the association of the early lymphocyte/neutrophil ratio with prognosis may result in better detection and more timely treatment of an abnormal immune status.

Our findings must be understood in view of the following limitations. First, this study had a relatively small sample size, even though it was the first study to explore the prognostic value of the lymphocyte/neutrophil ratio for prognosis in ARDS patients. Second, there may be a selection bias because only patients for whom absolute lymphocyte and neutrophil counts were measured soon after ARDS diagnosis were included. Third, the current study was not pre-specified but is a post hoc analysis from a retrospective controlled trial. Therefore, further prospective studies are needed.

\section{Conclusions}

We found age (per $\log _{10}$ years), BMI $<24$, the SOFA score, the lymphocyte count, and the lymphocyte/neutrophil ratio to be independent predictors of 100-day mortality in patients with ARDS. We also observed a moderate negative correlations between the lymphocyte/ neutrophil ratio and age, the SOFA score, and the APACHE II score, and a significant mild positive correlation between the lymphocyte count and BMI was also found. However, we detected a moderate positive correlation between the lymphocyte/neutrophil ratio and the $\mathrm{PaO}_{2} /$ $\mathrm{FiO}_{2}$ ratio in all patients with ARDS. The AUC was greatest for the lymphocyte/neutrophil ratio combined with the lymphocyte count for the prediction of 100-day survival in ARDS. In addition, the 28-day mortality rate of ARDS patients with a lymphocyte/neutrophil ratio < 0.0537 was higher than that with a ratio of lymphocyte/ neutrophil $\geq 0.0537$. The lymphocyte/neutrophil ratio was also revealed to be a strong and independent predictor of prognosis in ARDS patients, particularly in those with atypical immunodeficiency.

\footnotetext{
Abbreviations

ARDS: Acute respiratory distress syndrome; APACHE: Acute Physiology and Chronic Health Evaluation; AUC: Area under the curve; BALF: Bronchoalveolar lavage fluid; BMI: Body mass index; Cl: Confidence interval; CRP: C-reactive protein; ICU: Intensive care unit; LDH: Lactate dehydrogenase; MOF: Multiple organ failure; OR: Odds ratio; PCT: Procalcitonin; ROC: Receiver operating characteristic; SAPS: Simplified Acute Physiology Score; SD: Standard deviation; SOFA: Sequential Organ Failure Assessment
} 


\section{Author contributions}

All authors participated in the interpretation of the study results and review of the manuscript. MS designed and conducted all experiments, drafted the manuscript, and performed the statistical analyses. HL planned the study and drafted the manuscript. YJ L and ZW L participated in the data collection. HP and $P C$ contributed to the study design and the revision of the manuscript. All authors read and approved the final manuscript.

\section{Funding}

This work was supported by grants from by the National Natural Science Foundation of China (Grant number 81770002 and 81670062). Financial support was mainly provided for the collection and analysis of data and for staff costs

\section{Availability of data and materials}

The datasets used and analysed during the current study are available from the corresponding author on reasonable request.

\section{Ethics approval and consent to participate}

The study protocol was approved by the ethics committee of the Second Xiangya Hospital, Central South University (approval number: 2019150), and written informed consent was waived because of the retrospective design. All personal identification data were anonymized before analysis.

\section{Consent for publication}

Not applicable.

\section{Competing interests}

The authors declare that they have no competing interests.

\section{Author details}

'Department of Pulmonary and Critical Care Medicine, The Second Xiangya Hospital, Central South University, No.139 Renmin Road, Changsha 410011 Hunan, China. ${ }^{2}$ The Respiratory Disease Research Institute of Hunan Province; The Respiratory Disease Diagnosis and Treatment Center of Hunan Province, No.139 Renmin Road, Changsha 410011, Hunan, China. ${ }^{3}$ School of Mathematics and Statistics, Hunan Normal University, Changsha 410081, Hunan, China.

\section{Received: 12 July 2019 Accepted: 2 April 2020}

Published online: 23 April 2020

\section{References}

1. Thompson BT, Chambers RC, Liu KD. Acute respiratory distress syndrome. N Engl J Med. 2017;377:562-72

2. Definition Task Force ARDS, Ranieri VM, Rubenfeld GD, Thompson BT Ferguson ND, Caldwell E, Fan E, Camporota L, Slutsky AS. Acute respiratory distress syndrome: the Berlin Definition. JAMA. 2012;307(23):2526-33. https://doi.org/10.1001/jama.2012.5669.

3. Pipeling MR, Fan E. Therapies for refractory hypoxemia in acute respiratory distress syndrome. JAMA. 2010;304:2521e2527.

4. Guérin C, Reignier J, Richard JC, Beuret $P$, Gacouin A, Boulain T, Mercier E, Badet M, Mercat A, Baudin O, Clavel M, Chatellier D, Jaber S, Rosselli S, Mancebo J, Sirodot M, Hilbert G, Bengler C, Richecoeur J, Gainnier M, Bayle F, Bourdin G, Leray V, Girard R, Baboi L, Ayzac L, PROSEVA Study Group. Prone positioning in severe acute respiratory distress syndrome. N Engl J Med. 2013;368(23):2159-68. https://doi.org/10.1056/NEJMoa1214103.

5. Matthay MA, Ware LB, Zimmerman GA. The acute respiratory distress syndrome. J Clin Invest. 2012;122:2731-40.

6. Williams AE, Chambers RC. The mercurial nature of neutrophils: still an enigma in ARDS? Am J Physiol Lung Cell Mol Physiol. 2014;306:L217-30.

7. Williams AE, José RJ, Mercer PF, Brealey D, Parekh D, Thickett DR, O'Kane C, McAuley DF, Chambers RC. Evidence for chemokine synergy during neutrophil migration in ARDS. Thorax. 2017;72(1):66-73. https://doi.org/10. 1136/thoraxjnl-2016-208597.

8. Steinberg KP, Milberg JA, Martin TR, Maunder RJ, Cockrill BA, Hudson LD. Evolution of bronchoalveolar cell populations in the adult respiratory distress syndrome. Am J Respir Crit Care Med. 1994;150(1):113-22.

9. Grudzinska FS, Sapey E. Friend or foe? The dual role of neutrophils in lung injury and repair. Thorax. 2018;73(4):305-7. https://doi.org/10.1136/thoraxjnl2017-211253.
10. Adamzik M, Broll J, Steinmann J, Westendorf AM, Rehfeld I, Kreissig C, Peters J. An increased alveolar CD4 + CD25 + Foxp3 + T-regulatory cell ratio in acute respiratory distress syndrome is associated with increased 30-day mortality. Intensive Care Med. 2013;39(10):1743-51. https://doi.org/10.1007/ s00134-013-3036.

11. Cortegiani A, Madotto F, Gregoretti C, Bellani G, Laffey JG, Pham T, Van Haren F, Giarratano A, Antonelli M, Pesenti A, Grasselli G, LUNG SAFE Investigators and the ESICM Trials Group. Immunocompromised patients with acute respiratory distress syndrome: secondary analysis of the LUNG SAFE database. Crit Care. 2018 Jun 12;22(1):157. https://doi.org/10.1186/ s13054-018-2079-9.

12. Azoulay E, Soares M, Benoit D. Focus on immunocompromised patients. Intensive Care Med. 2016;42(3):463-5. https://doi.org/10.1007/s00134-016-4224-8.

13. Schmidt M, Schellongowski P, Patroniti N, Taccone FS, Reis Miranda D, Reuter J, Prodanovic H, Pierrot M, Dorget A, Park S, Balik M, Demoule A, Crippa IA, Mercat A, Wohlfarth P, Sonneville R, Combes A; International ECMO Network (ECMONet), the REVA Research Network and the IDEA Study Group. Six-month Outcome of Immunocompromised Severe ARDS Patients Rescued by ECMO. An International Multicenter Retrospective Study. Am J Respir Crit Care Med. 2018. doi: https://doi.org/10.1164/rccm.201708$17610 \mathrm{C}$.

14. Force ADT, Ranieri VM, Rubenfeld GD, Thompson BT, Ferguson ND, Caldwell E, Fan E, Camporota L, Slutsky AS. Acute respiratory distress syndrome: the Berlin Definition. JAMA. 2012;307(23):2526-33.

15. Knaus WA, Draper EA, Wagner DP, Zimmerman JE. APACHE II: a severity of disease classification system. Crit Care Med. 1985;13:818-29.

16. Vincent JL, Moreno R, Takala J, Willatts S, De Mendonça A, Bruining H, Reinhart CK, Suter PM, Thijs LG. The SOFA (Sepsis-related organ failure assessment) score to describe organ dysfunction/failure. On behalf of the working group on Sepsis-related problems of the European Society of Intensive Care Medicine. Intensive Care Med. 1996;22(7):707-10.

17. Nguyen $\mathrm{CQ}$, Yin $\mathrm{H}$, Lee $\mathrm{BH}$, Carcamo WC, Chiorini JA, Peck AB. Pathogenic effect of interleukin-17A in induction of Sjögren's syndrome-like disease using adenovirus-mediated gene transfer. Arthritis Res Ther. 2010;12:R220.

18. Anderson KC, Roach JA, Daley JF, Schlossman SF, Nadler LM. Dual fluorochrome analysis of human B lymphocytes: phenotypic examination of resting, anti-immunoglobulin stimulated, and in vivo activated B cells. J Immunol. 1986;136(10):3612-8.

19. Burgess LJ, Maritz FJ, Le Roux I, Taljaard JJ. Combined use of pleural adenosine deaminase with lymphocyte/neutrophil ratio. Increased specificity for the diagnosis of tuberculous pleuritis. Chest. 1996;109(2):4149.

20. Choi DH, Kobayashi Y, Nishi T, Luikart H, Dimbil S, Kobashigawa J, Khush K, Fearon WF. Change in lymphocyte to neutrophil ratio predicts acute rejection after heart transplantation. Int J Cardiol. 2018;251:58-64. https:// doi.org/10.1016/j.jijcard.2017.10.060

21. Bonizzoli M, Arvia R, di Valvasone S, Liotta F, Zakrzewska K, Azzi A, Peris A. Human herpesviruses respiratory infections in patients with acute respiratory distress (ARDS). Med Microbiol Immunol. 2016;205(4):371-9. https://doi.org/10.1007/s00430-016-0456-z.

22. Güell $E$, Martín-Fernandez $M$, De la Torre MC, Palomera E, Serra M, Martinez R, Solsona M, Miró G, Vallès J, Fernández S, Cortés E, Ferrer V, Morales $M$, Yébenes JC, Almirall J, Bermejo-Martin JF. Impact of Lymphocyte and Neutrophil Counts on Mortality Risk in Severe Community-Acquired Pneumonia with or without Septic Shock. J Clin Med. 2019 May 27;8(5). https://doi.org/10.3390/jcm8050754.

23. Brown KA, Brain SD, Pearson JD, Edgeworth JD, Lewis SM, Treacher DF. Neutrophils in development of multiple organ failure in sepsis. Lancet. 2006; 368(9530):157-69.

24. Shen XF, Cao K, Jiang JP, Guan WX, Du JF. Neutrophil dysregulation during sepsis: an overview and update. J Cell Mol Med. 2017;21(9):1687-97. https:// doi.org/10.1111/jcmm.13112 Epub 2017 Feb 28.

25. Mouillaux J, Allam C, Gossez M, Uberti T, Delwarde B, Hayman J, Rimmelé T, Textoris J, Monneret G, Peronnet E, Venet F. TCR activation mimics CD127lowPD-1high phenotype and functional alterations of T lymphocytes from septic shock patients. Crit Care. 2019;23(1):131. https://doi.org/10.1186/ s13054-018-2305-5.

26. Zhu G, Liu Y, Zhang W, Huang Y, Li K. CD27+TIM-1+ memory B cells promoted the development of Foxp3+ Tregs and were associated with better survival in acute respiratory distress syndrome. Immunol Res. 2018; 66(2):281-7. https://doi.org/10.1007/s12026-017-8983-2. 
27. Festic E, Bansal V, Kor DJ, Gajic O. US critical illness and injury trials group: lung injury prevention study investigators (USCIITG-LIPS). SpO2/FiO2 ratio on hospital admission is an indicator of early acute respiratory distress syndrome development among patients at risk. J Intensive Care Med. 2015; 30(4):209-16. https://doi.org/10.1177/0885066613516411.

28. Azoulay E, Mokart D, Pène F, Lambert J, Kouatchet A, Mayaux J, Vincent F, Nyunga M, Bruneel F, Laisne LM, Rabbat A, Lebert C, Perez P, Chaize M, Renault A, Meert AP, Benoit D, Hamidfar R, Jourdain M, Darmon M, Schlemmer B, Chevret S, Lemiale V. Outcomes of critically ill patients with hematologic malignancies: prospective multicenter data from France and Belgium--a groupe de recherche respiratoire en reanimation oncohematologique study. J Clin Oncol. 2013;31:2810-8.

\section{Publisher's Note}

Springer Nature remains neutral with regard to jurisdictional claims in published maps and institutional affiliations.

Ready to submit your research? Choose BMC and benefit from:

- fast, convenient online submission

- thorough peer review by experienced researchers in your field

- rapid publication on acceptance

- support for research data, including large and complex data types

- gold Open Access which fosters wider collaboration and increased citations

- maximum visibility for your research: over $100 \mathrm{M}$ website views per year

At BMC, research is always in progress.

Learn more biomedcentral.com/submissions 